\title{
Utilization of maternal and child health care interventions by rural poor mothers of Jammu \& Kashmir State of India
}

\author{
Neeru Sharma*, Meenakshi Anand, Ambika Sharma and Gulshan Kumari
}

\begin{abstract}
The Present study was conducted to understand the governmental health care interventions utilized by the rural mothers belonging to Below Poverty Line Families (BPL) of Jammu District of the State of Jammu and Kashmir. The objectives of the study were to assess the maternal and child health care practices followed by mothers during (a) Pre-natal period (b) Post-natal period (c) Infancy and early childhood; to know the awareness of mothers regarding various schemes implemented by the Government for welfare of women and children belonging to below poverty line families, and to know the utilization of maternal and child health care services by the mothers during their pregnancy and child care. The sample consisted of sixty mothers in the age group of $20-25$ years belonging to BPL families of Bishnah block of Jammu District, having a child in the age group of 0-3 years. The results revealed that most of the mothers followed many traditional practices during pregnancy and child rearing. They had immunized themselves and their children and had utilized the health services for post-natal consultation, though the immunization advice was not available to all of them. Most of the mothers preferred delivery in the hospitals. The children were mostly breast fed and weaning was done after six months of the birth. The mothers were not aware of many governmental schemes for maternal and child health even though they were availing benefits of these, due to interventions from health care workers.
\end{abstract}

Department of Home Science (Human

Development), University of Jammu, Jammu and Kashmir, India.

*Corresponding Email: neerusha@gmail.com
The grass root level health worker under the National Health Mission, ASHA (Accredited Social Health Activist), was delivering her services in these areas, as per the information provided by the respondents. She had prepared their health cards and was helping them in utilization of health care facilities during pregnancy and child birth. The other health providers consulted and health benefits received were also mentioned by the respondents. In spite of this most of the respondents appeared anaemic. Based on the findings, strategies have been suggested for the better coverage and utilization of health facility by the Below Poverty Line women.

\section{Keywords}

Women, Children, Health, Welfare Schemes, Below Poverty Line, Rural Area, Jammu, Jammu and Kashmir, India

\section{INTRODUCTION}

\section{Poverty in India:}

India is world's largest democracy and in recent years it has become second fastest growing economy. It is also estimated to have a third of the world's poor. According to the World Bank 1 in 5 Indians is poor and 80\% of India's poor live in rural areas (World Bank, 2016). Below Poverty Line is an economic benchmark and poverty threshold given by the Government of India to indicate economic disadvantages, and to identify individuals and household in need of government assistance and aid. In tenth plan (2002-2007) survey, BPL for rural areas was based on the degree of deprivation in respect of 13 parameters such as landholding, type of 
houses, clothing, food security, sanitation, literacy status, means of livelihood, status of children reasons for migration etc. According to 2011census of India 69\% of population resides in rural areas and among them women constitute about 48\% (Census of India, 2011). Almost $10.35 \%$ of the population falls under the below poverty line (BPL) category in Jammu and Kashmir, with the rural areas holding poorer than the urban areas (The Tribune, Jan 14, 2017).

According to the MDG Report (2015) the factors that contribute to women's heightened vulnerability to poverty include unequal access to paid work, lower earnings, lack of social protection and limited access to assets, including land and property. Even where women are equally as likely to live in poor households as men, they are more likely to be deprived in other important areas of well-being, such as education (MDG Report, 2015). The report further says that despite the progress in MMR, the MDG 5, and every day hundreds of women die during pregnancy or from childbirth-related complications. In 2013, most of these deaths were in the developing regions, where the maternal mortality ratio is about 14 times higher than in the developed regions. Globally, there were an estimated 289,000 maternal deaths in 2013, equivalent to about 800 women dying each day. Maternal deaths are concentrated in sub-Saharan Africa and Southern Asia, which together accounted for 86 per cent of such deaths globally in 2013 as per the MDG Report, 2015.

\section{Maternal Health Status in India}

The maternal mortality ratio (MMR) is defined as the number of maternal deaths during a given period per 100,000 live births during the same period. According to UNICEF, annually, it is estimated that 44,000 women die due to preventable pregnancy-related causes in India, but India's maternal mortality rate reduced from 212 deaths per 100,000 live births in 2007 to 167 deaths in 2013
(http://unicef.in/Whatwedo/1/Maternal-

Health). Maternal mortality is a key indicator for maternal health and reveals inequality between and also within states that cannot be attributed to biological differences alone. As per the SRS 2001-2003 the medical causes of Maternal Mortality can be direct or indirect. The most common direct medical causes of maternal deaths as per SRS (2001-2003) are haemorrhage, mainly postpartum (37\%), sepsis because of infection during pregnancy, labour, and postpartum period (11\%), unsafe abortions ( $8 \%)$, hypertensive disorders (5\%) and obstructed labour (5\%). These conditions are largely preventable and once detected, they are treatable. A significant proportion of maternal deaths are also attributed to 'indirect causes', the most common of which are anaemia and malaria. (Census of India, SRS 2001-2003). In a more recent review of selected maternal death cases, Subha Sri and Khanna (2014) found that about $26 \%$ of maternal deaths occurred at home, $25 \%$ occurred in transit, and $48 \%$ occurred at the health facility. The international community was committed to decrease the Maternal Mortality Ratio (MMR) by 75.0 percent by 2015 and improve overall maternal health care to achieve MDG-5. With one maternal death reported every ten minutes, India missed this Millennium Development Goal related to maternal health.

Vora et al (2009) conclude from their case study that India's goal is to lower maternal mortality to less than 100 per 100,000 live births, but that is still far away and they attribute it to the geographical vastness and socio-cultural diversity, which they say, means that maternal mortality varies across the states, and uniform implementation of health-sector reforms is not possible (Vora et al 2009). Most of the deliveries in India occur at home and without any assistance from skilled health professionals and hence majority of the maternal deaths occur because of the home delivery (IIPS,2010). Women's post-natal health appears to take 
second place for all once the process of child birth is over (Thomas,1998). The mothers who do not avail antenatal care and/ or give birth unattended by the trained personnel, invariably indulge into wrong practices related to child care and hence the child health complications adding to the infant mortality rate(IMR).

However, adolescent and illiterate mothers and those living in hard to reach areas still have a much greater chance of dying in childbirth. Adolescent girls outside Indian cities are especially vulnerable as teenage marriage and pregnancies are very high in rural and remote areas of the country (http://unicef.in/Whatwedo/1/Maternal-Health ). According to Joe et al (2015) high maternal mortality in India, particularly across empowered action group (EAG) states, is a critical policy concern. and several important initiatives have been rolled out under the Reproductive and Child Health (RCH) programme and National Rural Health Mission (NRHM). Despite such unprecedented attention, however, the reduction in MMR has been decelerating in recent times; and most maternal deaths in India continue to be associated with determinants such as nutrition, poverty, and socioeconomic marginalisation, over which policies have had little or no impact (Joe et al, 2015). NFHS 4 (2015-16) data indicates that in India the number of mothers who had full ante natal care were $31.3 \%$ in Urban areas, $16.7 \%$ in rural areas, $21 \%$ in total as compared to $11.6 \%$ in NFHS 3 conducted in 2005-06 (rchiips.org/NFHS/pdf/NFHS4/India.pdf). The NFHS 4 data further shows that $40.8 \%$ urban, $25.9 \%$ rural and $30 \%$ in total women consumed Iron/Folic Acid for 100 or more days almost double from $15.2 \%$ in NFHS 3. Post-natal care, from the doctor/nurse/LHV/ANM/midwife or other health personnel, was received by $71.7 \%$ urban women,.58.2\% rural women, $62.4 \%$ in total as per NFHS 4 as against $34.6 \%$ in NFHS3 and financial assistance under Janani Suraksha Yojna, for institutional deliveries, was received by $21.4 \%$ urban, $43.8 \%$ rural and $36.4 \%$ in total as per NFHS 4 . The current challenge is to identify and outline the role of governments, health and other sectors, communities, and households in population-wide strategies to improve access, delivery, and utilization of health care services (World Bank 2012; Jeffery and Jeffery 2010, as cited by Joe et al 2015).

Family being the smallest unit of society, the women are its backbones and the fulcrum. Poor pregnancy outcomes affect not only the mothers but also the child, family and community in all manners i.e. physically, mentally and economically. In Indian society where women's rights are repressed the health of women and children suffers significantly (Ganjiwale,2012). In the patriarchal system, prevalent in most parts of India, women's position is subordinate to that of men in various household decision-making matters, and this is ascertained by the customs and the traditions. This is also concretized through gender roles, relations, and unequal power in various household decision-making aspects. Maternal health, in this pretext, is also ingrained in this cultural context, where health seeking during this phase is not her own singular decision. It is the household's decision, and in case of nuclear families, the husband's decision, that's why in spite of so many health inputs the maternal health is not showing any improvement. Hence the present study was designed to understand the context of maternal and child health in a rural location among the families living in poverty.

\section{Child Health Status in India}

Assessing the MDG 4, reducing the child mortality rate, the MDG (2015) report says that every day in $2015,16,000$ children under five continued to die, mostly from preventable causes, hence child survival must remain the focus of the post-2015 development agenda. Assessing India's status on SDG, WHO (2017) found that both the Child Mortality Ratio and 
Neonatal Mortality Ratio have declined since the year 2000. They have almost halved till 2017CMR from 91 in 48 and NMR from 45 to 28 per 1000 live births (http://www.searo.who.int/entity/health situat ion trends/countryprofile ind.pdf?ua=1).

$38.4 \%$ children under 5 in India were found stunted, $21 \%$ wasted and only $1.9 \%$ overweight as per WHO (2017). As per the NFHS 4 statistics, children who received health check-up, from doctor/nurse/LHV/ ANM/midwife/ other health professionals, 2 days of birth were $27.2 \%$ in urban areas, $23 \%$ in rural areas, and $24.3 \%$ in total. The children who were underweight were $29.1 \%$ in urban areas, $38.3 \%$ in rural areas and $35.7 \%$ in total as compared to $42.5 \%$ in NFHS3. As per the NFHS 4 immunization status has improved a lot during the intervening period from NFHS 3.

MDG Report (2015) concludes that majority of neonatal deaths worldwide are caused by preterm birth complications ( 35 per cent), complications during labour and delivery (24 per cent) and sepsis (15 per cent). In subSaharan Africa and Southern Asia many deaths are also due to preventable infectious diseases. Many neonatal deaths could be avoided with simple, cost-effective and high-impact interventions that address the needs of women and new-borns across the continuum of care, with an emphasis on care around the time of birth. However, analysis shows that too many new-borns and mothers miss out on these key interventions (MDG Report, 2015). Mortality is more likely to strike children in rural areas as these children are about 1.7 times more likely to die before their fifth birthday as those in urban areas.

\section{Seeking Maternal Health Care by Women in India:}

Health seeking behaviour (HSB) is an important aspect of utilization of health services or benefits. Sanneving et al (2013) concluded that in India, economic status, gender, and social status are all closely interrelated when influencing use of and access to maternal and reproductive health care. Appropriate attention should be given to how these social determinants interplay in generating and sustaining inequity when designing policies and programs to reach equitable progress toward improved maternal and reproductive health (Sanneving et al., 2013). To enhance the understanding of how inequities in health are rooted in societal structures, the Commission on Social Determinants of Health (CSDH) developed a conceptual framework of the social determinants of health inequities (Solar et al., 2010). This is an action-oriented framework, applicable to identify entry points for interventions and policy that could reduce inequities in health in a specific setting. It is based on the notion that health inequities emerge from a systematically unequal distribution of power, prestige, and resources among groups in society. The framework is organized into three elements: socioeconomic and political context, structural determinants, and intermediary determinants. The structural determinants, or the social determinants of health inequity, operate through a series of intermediary social factors. These intermediary factors include material circumstances such as housing quality and physical environment, psychosocial circumstances such as stressful living conditions and relationships, (lack of) social support and coping styles, and behavioural and biological factors such as lifestyle and genetic factors. The health system is also described as a social determinant of health, particularly since it mediates the differential consequences of ill health (Solar et al., 2010). India spends a huge amount on health sectors with a large number of preventive and curative schemes for women but women's health indicators still show a poor trend, especially the reproductive health. The United Nations defines reproductive health as a "state of complete physical, mental and social well-being, and not merely the absence of reproductive disease or 
infirmity, in all matters relating to the reproductive system and to its functions and processes".

Seventy-four percent of women sought antenatal care (ANC) from a qualified provider and 52 percent of births were attended by qualified providers (El-Saharty et al, 2014). Wide gaps in contraceptive prevalence rate (CPR) and access to skilled-birth attendance remain by geography and wealth quintile. India will focus on preventing unwanted pregnancies especially among adolescents; improving demand-side strategies; strengthening access and quality in public and private sectors; improving antenatal, intranatal, and postnatal care; strengthening monitoring and evaluation ( $M$ and $E$ ) systems and reducing inequities; and improving nutrition (El-Saharty et al., 2014).

Devansenapathy et al. (2015) found that Compared to the poorest, the least poor women were more likely to be registered for ANC and more likely to have made $\geq 4$ ANC visits. They were more likely to have given birth in a facility, to have visited a hospital within one month of childbirth. In general, government funded health insurance and conditional cash transfers schemes were underutilized in this community. Study on the health-seeking behaviour (HSB) and utilization of health services by pregnant mothers in Vadodara slums reported that majority of women preferred private hospital for delivery in spite of being from lower socioeconomic group and most of the mothers ignored PNC ( Kotechal et al., 2012).A study by Manna et al.(2011) in Jalpaiguri and Darjeeling Districts, West Bengal reported that non-utilization or under-utilization of maternal health care services, especially among urban slum population are high due to lack of awareness or access to health care and this calls for understanding the HSB and utilization of services by those in need of them. Dandappanavar and Khan (2014) conducted a study in an urban slum of Dharwad town in Karnataka and reported that antenatal period is determined by religious beliefs and practices, which were learnt through the process of socialization. Apart from this literacy, education and exposure to mass media are less significant when it comes to the HSB because the people opine that pregnancy and childbirth are intertwined with the functions of religion, family, kinship and marriage.

An encouraging result, though, is seen in a study conducted by Arun et al (2017) on health seeking behaviour among married women of reproductive age group in a rural area was studied by community based cross sectional method. The health seeking behaviour of women in rural area was found to be satisfactory, as more than two-third of the study group has sought some treatment. They further conclude that more focus on educating the women, increasing their awareness towards health and highlighting the facilities and schemes in government health sectors will fill the gaps in health seeking behaviour. Large inequities remain in maternal health, along with gaps in access to and use of sexual and reproductive health services that must be consistently addressed and monitored. Hence the present study focused on the awareness among mothers, living below poverty line, about the schemes related to maternal and child health.

\section{OBJECTIVES}

1. To understand the context of maternal and child care among the families living below poverty line in the rural areas of Jammu during prenatal and post-natal periods and in infancy and early childhood years.

2. To know the awareness, access and utilization of health services by the rural mothers, belonging to Below Poverty Line (BPL) families, of Jammu District of the state of Jammu and Kashmir, India.

3. To know the rural mothers' awareness about the governmental schemes in operation for BPL Families especially for maternal and child health. 


\section{Research Methodology}

The study was conducted to understand the utilization of health acre interventions by the mothers, belonging to BPL families of Jammu, regarding the schemes for welfare of women and children.

1.SAMPLE: The sample for the present study comprised of 60 rural women having at least one child in the age group of birth to 3 years.

\section{Criteria for sample selection:}

i) Age of the reference child: Only those women were selected who were having at least one child in the age group of birth to three years.

ii) Area: The sample was selected only from the rural area of Bishnah block (administrative unit) of Jammu District of the state of Jammu and Kashmir in India.

iii) Financial Criteria: The sample consisted of only those women belonging to the BPL families as identified by Department of Rural Development, Government of Jammu and Kashmir.

\section{Sampling Techniques}

Multi-Stage Sampling Technique was used for the data collection. From Jammu District (Administrative Division) of Jammu and Kashmir state, Bishnah block was purposively selected. Out of 130 villages of this block, only six villages namely Adlehar, Allah, Chak Fateh Khan, Pandori, Karyal and Shibu Chak were selected randomly. Then the list of BPL families, residing in these areas, was obtained from the Department of Rural Development, Government of Jammu and Kashmir, and from each village, women fulfilling the criteria for sample selection were listed. Out of the list ten women were randomly selected from each village.

\section{TOOL USED:}

a. Interview with the Block Medical Officer:

The Block Medical Officer, Bishnah was interviewed about schemes regarding care of mother and child health operational in his block.

\section{b. Interview Schedule for mothers:}

As per the governmental initiatives, MDG Report, and other studies conducted in the area, some of the key indicators for maternal health are antenatal check-up, institutional delivery and delivery by trained and skilled personnel, postnatal care etc., hence a self-structured interview schedule was prepared covering these areas. The main components were:

i). Background information: This part of interview schedule helped to know about age, education, qualification and occupation of the respondents and their family.

ii). Information regarding family: This part includes the type of family and number of child etc.

iii). Practices related to pre-natal period and role of Governmental schemes. iv). Practices related to post-natal period and role of Governmental schemes. v). Practices related to Early Childhood. vi). Mothers awareness about the governmental schemes in operation for mother and child health.

vii) Mothers report of role of various health providers during pregnancy and child care.

\section{DATA COLLECTION:}

The tools were given to experts for their opinion and the suggestions were incorporated. Pretesting of the tool was done on a similar sample. The necessary modifications were made before the actual data collection. Data was collected through home visits. To establish rapport the help of the local health worker was sought. The researcher visited the women along with the local health workers. After initial ice-breaking another visit was made to collect the information. It took about one hour to carry out a single interview. Some of the respondents were not able to give responses to some questions in the interview. They were made comfortable and were told that they should not be embarrassed if they are unable to answer any question. After the initial ice breaking the 
interviewing process went on smoothly. The interviews were conducted in the local language "Dogri" to make the process more comfortable for the respondents, as most of them were having low level of education.

\section{DATA ANALYSIS:}

The raw data thus obtained was consolidated through coding and tabulation. After that the data was subjected to descriptive analysis using frequencies and the analysis has been

presented in the form of tables and diagrams.

\section{RESULTS AND DISCUSSION}

BACKGROUND INFORMATION ABOUT THE RESPONDENTS:

\begin{tabular}{|c|c|c|}
\hline Background variables & Frequencies & Percentage (\%) \\
\hline \multicolumn{3}{|l|}{ Age (in years) } \\
\hline $20-25$ & 29 & 48.36 \\
\hline $25-30$ & 26 & 43.34 \\
\hline $30-35$ & 4 & 6.67 \\
\hline $35-40$ & 1 & 1.6 \\
\hline \multicolumn{3}{|c|}{ Educational Qualifications of Respondents } \\
\hline Illiterate & 7 & 11.67 \\
\hline Upto $5^{\text {th }}$ & 3 & 5 \\
\hline $8^{\text {th }}$ & 26 & 43.34 \\
\hline $10^{\text {th }}$ & 23 & 38.34 \\
\hline $12^{\text {th }}$ & 1 & 1.67 \\
\hline \multicolumn{3}{|l|}{ Type of family } \\
\hline Joint & 37 & 61.67 \\
\hline Nuclear & 23 & 38.34 \\
\hline \multicolumn{3}{|l|}{ Number of children } \\
\hline 1 & 26 & 43.34 \\
\hline 2 & 26 & 43.34 \\
\hline 3 & 7 & 11.67 \\
\hline 4 & - & - \\
\hline 5 & 1 & 1.67 \\
\hline \multicolumn{3}{|c|}{ Age of children* (in years) } \\
\hline $0-3$ & 60 & 100 \\
\hline $3-6$ & 26 & 43.33 \\
\hline $6-9$ & 7 & 11.67 \\
\hline Above 9 & 7 & 11.67 \\
\hline
\end{tabular}

Table 1 Background information about the respondents. * Multiple responses

Table 1 shows that $48.36 \%$ of the respondents were in the age group of 20-25 years, and $43.34 \%$ were in the age group of $25-30$ years.
Forty three percent of the respondents were educated up to eighth standard, $38.34 \%$ of them were educated up to 10 th standard, $11.67 \%$ 
were illiterate, $5 \%$ were educated up to 5 th standard and only $1.67 \%$ of mothers were educated up to 2 th standard. Sixty two percent of the respondents were living in joint and $38.34 \%$ in the nuclear families. Forty three percent of the respondents had one child, $43.34 \%$ had two children and $11.67 \%$ mothers

\begin{tabular}{|c|c|c|}
\hline Practices followed during the Prenatal Period & Frequency $(\mathrm{N}=60)$ & Percentage (\%) \\
\hline \multicolumn{3}{|l|}{ Changes in food consumption pattern } \\
\hline Yes & 50 & 83.33 \\
\hline \multicolumn{3}{|l|}{ Foods Added } \\
\hline Milk/green leafy vegetable & 39 & 65 \\
\hline Dry fruit & 11 & 18.34 \\
\hline No change & 10 & 16.67 \\
\hline \multicolumn{3}{|l|}{ Hygiene related practices } \\
\hline \multicolumn{3}{|l|}{ a) Bathing during pregnancy } \\
\hline Everyday & 45 & 75 \\
\hline Every other day & 15 & 25 \\
\hline \multicolumn{3}{|c|}{ b) Brushed teeth in the morning before eating anything } \\
\hline Yes & 60 & 100 \\
\hline \multicolumn{3}{|l|}{ c)Washed hands before eating } \\
\hline Yes & 60 & 100 \\
\hline \multicolumn{3}{|l|}{ d)Cut nails } \\
\hline Yes & 60 & 100 \\
\hline \multicolumn{3}{|l|}{ Health related practices } \\
\hline \multicolumn{3}{|l|}{ a) Took proper rest } \\
\hline Yes & 57 & 95 \\
\hline No & 3 & 5 \\
\hline \multicolumn{3}{|l|}{ b) Avoided picking up heavy things } \\
\hline Yes & 54 & 90 \\
\hline No & 6 & 10 \\
\hline \multicolumn{3}{|l|}{ c) Advised to walk } \\
\hline Yes & 41 & 68.34 \\
\hline No & 19 & 31.56 \\
\hline \multicolumn{3}{|l|}{ d) Monitored weight (during pregnancy) } \\
\hline Yes & 60 & 100 \\
\hline \multicolumn{3}{|l|}{ Weight during pregnancy } \\
\hline $30-40$ & 6 & 10 \\
\hline $40-50$ & 36 & 60 \\
\hline $50-60$ & 8 & 13.34 \\
\hline Don't know & 10 & 16.67 \\
\hline
\end{tabular}

were having five children. All the respondents had the children in the age group of 0-3 years, $43 \%$ families had children in the age group of $3-$ 6 years, $11.67 \%$ each had children in the age group was 6-9 years and above 9 years of age, respectively. 
PRE-NATAL PERIOD:

Table No :2 shows that $83.33 \%$ of respondents had brought changes in their food consumption patterns during pregnancy. $65 \%$ of the respondents added green leafy vegetables and milk, $18.34 \%$ of respondents added dry fruit, whereas $16.67 \%$ of respondents made no changes in their food intake. Seventy five percent of respondents bathed every day during pregnancy whereas $25 \%$ of respondents had bath every alternate day.

All respondents brushed their teeth before eating anything in the morning and kept their

\begin{tabular}{|c|c|c|}
\hline Role of doctor & Frequency $(\mathrm{N}=60)$ & Percentage (\%) \\
\hline \multicolumn{3}{|c|}{ How was the pregnancy confirmed? } \\
\hline By visit to a doctor & 42 & 70 \\
\hline $\begin{array}{l}\text { Through symptoms (Nausea \& } \\
\text { vomiting) }\end{array}$ & 18 & 30 \\
\hline \multicolumn{3}{|l|}{ Consulted doctor from } \\
\hline Urban Area & 54 & 90 \\
\hline Own Village & 6 & 10 \\
\hline \multicolumn{3}{|l|}{ Took doctors' advice } \\
\hline Yes & 60 & 100 \\
\hline \multicolumn{3}{|l|}{ Followed doctor's prescription } \\
\hline Yes & 60 & 100 \\
\hline \multicolumn{3}{|l|}{ Weight measured by doctor } \\
\hline Yes & 49 & 81.67 \\
\hline Others & 11 & 18.34 \\
\hline \multicolumn{3}{|c|}{ Doctor advised consuming green leafy vegetable } \\
\hline Yes & 58 & 96.67 \\
\hline No & 2 & 3.34 \\
\hline \multicolumn{3}{|c|}{ Consulted doctor for any problem during pregnancy } \\
\hline Yes & 60 & 100 \\
\hline \multicolumn{3}{|l|}{ Frequency of consulting doctor } \\
\hline Twice in a month & 35 & 58.34 \\
\hline When required & 25 & 41.67 \\
\hline \multicolumn{3}{|c|}{ Received maternal tetanus vaccination } \\
\hline Yes & 60 & 100 \\
\hline
\end{tabular}

Table 3 Role of health providers during pre-natal period 
Table 3 shows that $70 \%$ of respondents had received the confirmation of their pregnancy by a doctor and $30 \%$ of respondents detected pregnancy from the symptoms such as nausea and vomiting. Majority (90\%) of the respondents consulted doctors from urban areas near their villages, whereas $10 \%$ consulted doctor from their own village only. All the respondents consulted and followed the doctor's advice and prescription during pregnancy. Eighty two percent of the respondents said that the doctor used to measure their weight during pregnancy, for the rest ASHA, Anaganwadi Worker or someone else measured it. Majority $(96.67 \%)$ of the respondents were advised by the doctor to consume green leafy vegetables. All the respondents had consulted doctor in case of any problem during pregnancy, though the frequency varied, $58.34 \%$ of the respondents consulted doctor twice in a month and $41.67 \%$ of respondents consulted doctor only when required. All the respondents said that they had received maternal tetanus vaccination. Table 4 shows that $66.67 \%$ of the respondents suffered from mild illness during pregnancy like nausea, $18.34 \%$ suffered from fainting and $10 \%$ from vomiting. Forty three percent of respondents reported that they were anaemic (kat khoon ha ) during pregnancy.

\begin{tabular}{|l|l|l|}
\hline Responses & Frequency (N=60) & Percentage (\%) \\
\hline Any illness during pregnancy? & \multicolumn{2}{|l|}{} \\
\hline Nausea & 46 & 66.67 \\
\hline Vomiting & 6 & 10 \\
\hline Fainting & 11 & 18.34 \\
\hline Were you anaemic? & 26 & 43.34 \\
\hline Yes & 34 & 56.67 \\
\hline No & \multicolumn{2}{|l|}{} \\
\hline
\end{tabular}

Table 4 Mother's health during pregnancy period.

Table 5 shows that $88.34 \%$ of respondents preferred Government Hospitals for treatment and $11.67 \%$ of respondents preferred Private Hospitals. All the respondents preferred normal delivery, but $36.67 \%$ of them actually had their delivery either through caesarean section or minor surgery (as they call it), $63.34 \%$ of the respondents had a normal delivery. Sixty two percent of respondents said that they preferred hospital delivery because of the availability of all facilities, $38.34 \%$ of respondents said that they preferred home delivery because of the fear of operation (caesarean section), few cited the lack of emotional support in the institutional settings as the reason for favoring home delivery and few cited financial problems for preferring home delivery. Delivery of $80 \%$ of respondents took place in hospital and $20 \%$ of respondents had their delivery at home. During home delivery
$8.34 \%$ of respondents said that the doctor was present and $11.67 \%$ of respondents said that Dai (mid-wife) was present at the time of delivery.

Table No 6 shows the role of ASHA or Accredited Social Health Activist who works under the National Health Mission for promotion of Maternal and Child Health in India. Majority (93.34\%) of respondents said that ASHA visited them during their pre-natal period and registered their names, advised them to consult doctor and told them to take prescribed medicines regularly. Eighty seven percent of respondents said that ASHA advised them to take iron and calcium tablets (supplements). Majority (83.34\%) of respondents said that ASHA suggested them to opt for institutional delivery but $53.34 \%$ of them said that ASHA did not advise them to have proper check up by the 
doctor after delivery.

\begin{tabular}{|l|l|l|}
\hline Responses & Frequency (N=60) & Percentage (\%) \\
\hline Preference for type of health care facility & 88.34 \\
\hline Government & 53 & 11.67 \\
\hline Private & 7 & 100 \\
\hline Type of delivery preferred & 60 & 36.67 \\
\hline Normal & \multicolumn{2}{l|}{} \\
\hline Type of delivery that actually took place & 63.34 \\
\hline Caesarean & 22 & 38.34 \\
\hline Normal & 38 & 61.67 \\
\hline Place of delivery preferred & 23 & \multicolumn{2}{|l|}{} \\
\hline At home & 37 & 80 \\
\hline Hospital & \multicolumn{2}{|l|}{} \\
\hline Actual place of delivery & 48 & 8.34 \\
\hline Hospital & 12 & 11.67 \\
\hline At home & 5 & \\
\hline If home delivery, healthcare personnel present at the time & \\
\hline Doctor & 5 & \\
\hline Mid wife & 7 &
\end{tabular}

Table 5 Place and type of delivery.

\begin{tabular}{|l|l|l|}
\hline ASHA's role & Frequency (N=60) & Percentage (\%) \\
\hline ASHA visited during pregnancy & 56 & 93.34 \\
\hline Yes & 4 & 6.67 \\
\hline No & \multicolumn{2}{|l|}{} \\
\hline Registered name at the time of pregnancy & 93.34 \\
\hline Yes & 56 & 6.67 \\
\hline No & 4 & \multicolumn{2}{|l|}{} \\
\hline ASHA advised & \multicolumn{2}{|l|}{} \\
\hline a)To consult doctor during pregnancy & 93.34 \\
\hline Yes & 56 & 6.67 \\
\hline No & 4 & 86.67 \\
\hline b)Take proper supplementation of iron and calcium & 13.34 \\
\hline Yes & 52 & \\
\hline No & 8 & 83.34 \\
\hline c)To have delivery in hospital & 50 & 16.67 \\
\hline Yes & 10 & \\
\hline No & 28 & 56.64 \\
\hline d) To have proper health check -up after delivery & 53.34 \\
\hline Yes & 28 & \\
\hline No & 32 & \\
\hline
\end{tabular}

Table 6 Mother's report on role of ASHA (Accredited Social Health Activist) during pre-natal period. 


\begin{tabular}{|l|l|l|}
\hline Role of ANM & Frequency (N=60) & Percentage (\%) \\
\hline ANM advised you for regular checkup? & 100 \\
\hline Yes & 60 & 100 \\
\hline Did you go for regular check up? & 60 & 50 \\
\hline Yes & \multicolumn{2}{l}{} \\
\hline ANM suggested you to have delivery in hospital? & 50 \\
\hline Yes & 30 & 5 \\
\hline No & 30 & 33.34 \\
\hline Advised about immunization after delivery & 66.67 \\
\hline Yes & 20 & \\
\hline No & 40 & \\
\hline
\end{tabular}

Table7 Mothers report on the role of Auxiliary Nurse Mid Wife (ANM) during pre-natal period.

Table 7 shows that when the respondents were taken to the hospitals by the ASHA, the ANM present there provided them advice related to pregnancy and birth process and regular checkups. All of them followed ANM's advice. In $50 \%$ of the cases the respondents were advised by ANM's to have delivery in hospitals. Only in $33.34 \%$ cases the ANM's advised the respondents for immunization of the child after delivery, but some respondents said that they did not consult the ANM's, they directly consulted doctors regarding the immunization.

\begin{tabular}{|l|l|l|}
\hline $\begin{array}{l}\text { Ceremony } \\
\text { performed }\end{array}$ & $\begin{array}{l}\text { Frequency } \\
(\mathbf{N}=60)\end{array}$ & $\begin{array}{l}\text { Percentage } \\
(\mathbf{\%})\end{array}$ \\
\hline Yes (Reetein) & 22 & 36.67 \\
\hline No & 38 & 63.34 \\
\hline
\end{tabular}

Table 8 Ceremonies performed during pregnancy.

Table 8 shows that the ceremony before birth of the child, known as reetein, similar to baby shower in West, was performed in only $36.67 \%$ cases during pregnancy. The ceremony 'reetein' (godh bharayee) is performed during the 8th month of pregnancy, to mark the wellness of the mother and child, and the safe arrival of the time of delivery. In this ceremony people shower blessing on the unborn child and the mother and give the mother gifts in the form of money, dry fruits, fruits, clothes etc. The family of the expectant mother arranges a party (dhaam in local language) and serves the traditional food to their guests. Sixty three percent respondents said that no ceremony was performed during pregnancy as they did not have resources for that.

\section{POST-NATAL PERIOD:}

Table 9 shows that the height and weight of all the new-borns was measured after birth and the respondents were informed that it was normal, even though the birth took place at home in some cases. In all cases the Child Care Card was prepared by the ASHA, but the respondents were not able to give correct information regarding the height or weight because they were unable to locate the Child Care Card. Sixty five percent of the respondents had been provided information about immunization by ASHA, $15 \%$ of respondents were given this information by the doctors, $10 \%$ each of the respondents by ANM and family members, respectively, though at the time of health checkups the ANM's did advise them about immunization. Forty three percent of respondent had received information about Polio Vaccination from television, 35\% from ASHA, 8.34\% from Anganwadi Workers and $6.67 \%$ each from doctors and family members, respectively. All the respondents had immunized their new-borns against polio. All respondents consulted doctors during their child illness. 


\begin{tabular}{|l|l|l|}
\hline Post-natal health care of infant & Frequency (N=60) & Percentage (\%) \\
\hline Height and weight of the newborn measured after delivery? & 100 \\
\hline Yes & 60 & 100 \\
\hline Informed that height and weight was normal? & \multicolumn{2}{l|}{} \\
\hline Yes & 60 & 65 \\
\hline Information about immunization provided by: & 15 \\
\hline ASHA & 39 & 10 \\
\hline Doctor & 9 & 10 \\
\hline Family member & 6 & \multicolumn{2}{|l|}{} \\
\hline ANM & 6 & 43.35 \\
\hline Information about polio drops given by: & 35 \\
\hline Television & 26 & 8.34 \\
\hline ASHA & 21 & 6.67 \\
\hline Anganwadi worker & 5 & 6.67 \\
\hline Doctor & 4 & 100 \\
\hline Family member & 4 & 100 \\
\hline Polio drops administered to infant child & \multicolumn{2}{|l}{} \\
\hline Yes & 60 & 1 \\
\hline Consult doctor during childcare /illness & 60 & 1 \\
\hline Yes & 60 & \\
\hline
\end{tabular}

Table 9 Post-natal care and advice provided to the mothers by health staff

\begin{tabular}{|l|l|l|}
\hline Variables & Frequency (N=60) & Percentage (\%) \\
\hline Prelacteal Food Given to the infant & 34 & 56.67 \\
\hline Honey & 24 & 40 \\
\hline Jaggery & 2 & 3.34 \\
\hline Sugar & \multicolumn{2}{|l|}{} \\
\hline Infant bathed for the first time after delivery & 85 \\
\hline After 5 days & 51 & 15 \\
\hline After 10 days & 9 & \multicolumn{2}{|l|}{} \\
\hline Massaging of the infant & 100 \\
\hline Yes & 60 & 100 \\
\hline Colostrums given & \multicolumn{2}{|l|}{} \\
\hline Yes & 60 & 100 \\
\hline Feeding preferred for the child & 60 & 100 \\
\hline Breast Feeding & \multicolumn{2}{|l}{} \\
\hline Weaning done after the age of & 60 & 100 \\
\hline 6 months &
\end{tabular}

Table 10 Practices related to post delivery, feeding, weaning. 


\section{PRACTICES FOLLOWED DURING INFANCY}

Table 10 shows that $56.67 \%$ of the respondents' infants were given prelacteal food in the form of honey and $40 \%$ in the form of jaggery. There is a belief that the child should be given prelacteal foods to clear his digestive and respiratory system and also to imbibe sweetness in his/her behaviour. Eighty five percent of the infants were bathed five days after the delivery. Mothers preferred breast feeding and all of them gave the colostrums for healthy development of the child. Weaning was done after 6 months of the age of the child, mostly with water from cooked rice (pich) or Pulses ( $d a l$ ka paani).

\begin{tabular}{|l|l|l|}
\hline Variables & Frequency (N=60) & Percentage (\%) \\
\hline At what age was the child was fully toilet trained? & 33.34 \\
\hline 2years & 20 & 66.67 \\
\hline 3years & 40 & 30 \\
\hline At what age they started going independently to the toilet? & 70 \\
\hline 2 1/2 years & 18 & \multicolumn{2}{|l|}{} \\
\hline 3 years & 42 & 100 \\
\hline Does the child have fixed routine for going to the toilet? & \multicolumn{2}{|l|}{} \\
\hline Yes & 60 & 78.34 \\
\hline Are you aware of the preventive vaccines to be given to the child? & 21.67 \\
\hline Yes & 47 & \multicolumn{2}{|l|}{} \\
\hline No & 13 & \\
\hline
\end{tabular}

Table 11 Early childhood care beliefs and practices followed by the respondents

\section{EARLY CHILDHOOD CARE BELIEFS AND PRACTICES}

Table 11 shows that $66.67 \%$ of respondents had fully toilet trained their child at the age of three years and $33.34 \%$ of the respondent's toilet trained their child at the age of two and a half years. Seventy percent mothers had started to let their child go to toilet independently by the age of three years and $30 \%$ of the respondents started it at the age of two and a half years. All the respondents said that their children had a fixed routine for going to the toilet. Seventy eight percent of the respondents were aware of the preventive vaccines given to the child at this age but $21.67 \%$ of the respondents were unaware of such preventive vaccines.

\section{MOTHERS AWARENESS ABOUT THE WELFARE} SCHEMES
Table 12 shows that all the respondents were BPL cardholders and they know the criteria for BPL card. Eighty eight percent respondents were not aware of any type of schemes or benefits that the government is providing for them or their children's and $11.6 \%$ of respondents do know about these, though none of them could name the schemes. Fifty three percent of respondents said that ASHA educate them about various governmental schemes. Fifty eight percent of the respondents did not know that there were cash incentives for delivery and the rest said that they had taken Rs. 1400 after delivery. Sixty eight percent of respondents did not get any special funds for their children under such schemes meant for them, and only $18.3 \%$ got some special funds for their children under such schemes. Fifty percent of the respondents said that they were aware about how much they 
are required to pay for $1 \mathrm{~kg}$ ration and $50 \%$ were unaware about this. Sixty five percent of respondents said that they have to pay only half of the fee of their treatment in government hospitals and $35 \%$ were unaware about it. $86.67 \%$ of respondents said that they were not

\begin{tabular}{|c|c|c|}
\hline Variables & Frequency $(\mathrm{N}=60)$ & Percentage (\%) \\
\hline \multicolumn{3}{|l|}{ Are you BPL card holder? } \\
\hline Yes & 60 & 100 \\
\hline \multicolumn{3}{|c|}{ Do you know what the criteria for BPL card is? } \\
\hline Yes & 60 & 100 \\
\hline \multicolumn{3}{|c|}{ Do you know the benefits government is providing to you and your children? } \\
\hline Yes & 7 & 11.6 \\
\hline No & 53 & 88.3 \\
\hline \multicolumn{3}{|c|}{ What type of demand are you putting in the front of the government? } \\
\hline Job opportunity & 23 & 38.3 \\
\hline Small business for women & 3 & 5 \\
\hline No demand & 34 & 56.6 \\
\hline \multicolumn{3}{|c|}{$\begin{array}{l}\text { Does ASHA worker educate you about various schemes launched by the government for pregnant } \\
\text { women? }\end{array}$} \\
\hline Yes & 32 & 53.3 \\
\hline No & 28 & 46.6 \\
\hline \multicolumn{3}{|c|}{ Do you know how much cash incentive is there for an institutional delivery? } \\
\hline Yes & 25 & 41.6 \\
\hline No & 35 & 58.3 \\
\hline \multicolumn{3}{|c|}{ How much cash did you take after delivery? } \\
\hline 1400 & 25 & 41.6 \\
\hline \multicolumn{3}{|c|}{ Are you getting any special fund for your children from these schemes? } \\
\hline Yes & 11 & 18.3 \\
\hline No & 41 & 68.3 \\
\hline \multicolumn{3}{|c|}{ Are you aware how much you have to pay for $1 \mathrm{~kg}$ ration? } \\
\hline Yes & 30 & 50 \\
\hline No & 30 & 50 \\
\hline \multicolumn{3}{|c|}{ Should you pay for treatment in Governmental Health Care Units? } \\
\hline Yes & 39 & 65 \\
\hline No & 21 & 35 \\
\hline \multicolumn{3}{|c|}{ Do you know government provides you loan for starting small businesses? } \\
\hline Yes & 8 & 13.34 \\
\hline No & 52 & 86.67 \\
\hline \multicolumn{3}{|c|}{ Do you know SGSY provides you with additional job opportunity? } \\
\hline Yes & - & - \\
\hline No & 60 & 100 \\
\hline
\end{tabular}

aware about the loans provided by the government for small business whereas $13.34 \%$ of respondents were aware about such government loans. 


\section{DISCUSSION}

Poverty often leads to lack of access to the basic necessities such as food, shelter and medical care. Maternal Health is an important aspect for the development of any country in terms of increasing equity and reducing poverty. The survival and wellbeing of mothers are not only important in their own right but also central to solving broader, economic, social and developmental challenges (Annual Report 201314).

The National Health Mission (NHM) with its two Sub-Missions, the National Rural Health Mission (NRHM) and the National Urban Health Mission (NUHM) was approved by the Cabinet in May, 2013. The NHM envisages universal access to equitable, affordable and quality healthcare services that are accountable and responsive to people's needs. The main programmatic components include Health System Strengthening in rural and urban areas, Reproductive- Maternal- Newborn- Child and Adolescent Health ( $\mathrm{RMNCH}+\mathrm{A})$ and control of Communicable and Non-Communicable Diseases. Jammu and Kashmir have been identified as a Low Performing State by the NHM under the Janani Suraksha Yojna (JSY) because of less than $25 \%$ institutional delivery rate. JSY is a safe motherhood intervention under the National Rural Health Mission (NHM) launched in the year 2005. It is being implemented with the objective of reducing maternal and neonatal mortality by promoting institutional delivery among poor pregnant women. Government of India has launched Janani Shishu Suraksha Karyakaram (JSSK) on 1st June, 2011. The incentives include free-delivery, C-Section, drugs and consumables, diagnostics, diet during stay in the health institutions, provision of blood, exemption from user charges, transport from home to health institutions, transport between facilities in case of referral, drop back from Institutions to home after $48 \mathrm{hrs}$ stay. The treatment of the new-born in case of sickness till 30 days of birth is treatment, drugs and consumables, diagnostics provision of blood, exemption from user charges, transport from home to health institutions, transport between facilities in case of referral, drop back from institutions to home.

The present research was focused on knowing the utilization of the schemes for maternal and child health among rural mothers of BPL families of Jammu. Interview schedules were used for data collection. The researchers visited the office of the Block Medical Officer, BMO, at the initial stage of the research. He informed the researchers that the Janani Suraksha Yojana and Janani Shishu Suraksha Karyakram were implemented in their block for the care of mother and child. For data collection from the respondent mothers home visits were made after the identification of the sample.

Most of the respondents were young and in the reproductive age, with most of them having low level of education, living in joint families and having 2 offspring. All the respondents were home makers. Their husbands were mostly daily wagers earning a meagre amount, not enough for even for meeting day to day expenses. Most of their offsprings were males. The mothers had access to the health services and were following the advice given by the doctors, whom they consulted at the behest of ASHA. Birth registrations were done for all by ASHA. The health status of the mothers during pregnancy, as reported by them showed that they suffered from mild illness but many were anaemic in spite of consulting the doctors. Most of them were underweight during their pregnancy and on observation too they looked underweight at the time of data collection. They did not observe prebirth traditional ceremonies, markers of safe pregnancy, due to lack of resources. They had modified their food consumption pattern and had been vaccinated against tetanus. They were following hygienic practices too but most of them were underweight. Measuring weight is a taboo among the expectant mothers as it is 
believed that an evil eye will cast its bad influence on the mother and child.

In a country where population is in billions, people still fear the evil, as it may cause harm to their unborn child, a child who should preferably be a male, as females have to be sent to other households after marriage. It's the protection of the unborn son that is done by following such beliefs and practices. Females are believed to be strong at the time of birth, so even after the birth of the child weight or height measurement, and disclosure of that is considered to invite the spell of evil eye. The mothers and grandmothers prefer saying "kamjor ae" (the infant is weak).

The respondents consult doctors at the advice of the ASHA, but sometimes the people refer to Registered Medical Practitioner (RMP) or the person owning a Medicine Shop as a Doctor too, and many times it is observed that they seek advice from them when they have medical problems, as they don't have finances to visit block hospitals or Primary Health Centres (PHC).The mothers are not aware that even the government is providing finances for early registration, delivery and follow ups at medical facilities. Respondents preferred delivery in government hospitals as they consider them safe. Poverty seems to be one of the reasons for choosing home deliveries because of the cost incurred on the institutional deliveries, even if they happen in the government facilities. A household survey from Chandigarh Union Territory comparing coverage of maternal health care showed that among the women studied, only $32 \%$ of the women living in urban-slum areas had an institutional delivery, compared to $93 \%$ of the non-slum urban women, and $79 \%$ of the women living in rural areas (Gupta et al 2008). Most of the respondents had a normal delivery; home delivery was preferred by a few women but in the presence of a doctor or a mid- wife. A study using the National Sample Survey from 2004 showed that a vast majority of the poorest households in the country paid more than $40 \%$ of their capacity to pay for maternal health services (Bonu et al., 2009). Gupta et al. (2008) reported that about $68 \%$ of the deliveries were at home and not assisted by a skilled birth attendant (nurse, midwife, or doctor) in the slums, compared to $21 \%$ and $7 \%$ in rural and urban areas $(p<0.001)$, respectively. In the present study many respondents also had home deliveries, though in the presence of a doctor or dai (mid wife). Fear of operation (Cesarean section) and lack of emotional support were cited as reasons for preferring home deliveries, by the respondents of the present study. In a study by Griffiths and Stephenson (2001), too, respondents identified the poor quality of services offered at government institutions to be a motivating factor for delivering at home.

The most commonly cited reasons for home birth were custom and lack of time to reach a healthcare facility during labour. Seventy percent of home deliveries were assisted by a traditional birth attendant (dai), and $6 \%$ by skilled health personnel (Das et al 2010). Home births are frequent among the urban poor and fear of hospitals (36\%), comfort of home (20.7\%) and lack of social support for child care (12.2\%) emerged as the primary reasons for home births (Devasenapathy, 2014). Though initiatives like JSY and JSSK and the recent Maternity Benefit Programme- Conditional Maternity Benefit, implemented in India in 2017, have encouraged the women to seek health care at institutions, yet a lot needs to be done still because the studies carried till recently, along with the present study, show that still there are some reservations -personal, cultural, economic and social- which inhibit women from institutional deliveries. 
Mother's education remains the most powerful determinant of inequality in survival. Children of mothers with secondary or higher education are almost three times as likely to survive as children of mothers with no education (MDG Report,2015) and poverty results in low level of education, as can be seen among the mothers in the present study too.

The respondents of the present study have access to the health services and they have utilized these, though a further in-depth study is required to understand the frequency and amount of utilization and the benefits accrued by the pregnant and lactating mothers. All of them have visited the doctor during their pregnancy, though the frequency varied, yet it cannot be concluded that they are aware of the health care facilities available to them because many still had their deliveries at home and were not eligible for CMB (Conditional Maternity Benefit), where early registration, institutional deliveries and referral are essential. CMB has been launched to encourage institutional delivery and some conditions are attached to it so that the recipients take full coverage of the health facilities available to them. The scheme envisages providing cash incentive amounting to Rs 6000/-, transferred to the bank accounts of the beneficiary directly, during their pregnancy, childbirth and lactation period, provided they register early, go in for at least one ante natal check-up, register the birth of their child and immunize the child. Their underweight status and their responses show that post-natal care was not accessed by them, though according to them they had sought care during pre-natal period. The Child Care Card had been prepared after all deliveries, by the ASHA, yet the mothers had not kept it safe and it may be concluded that they have not immunized their children fully, against the prescribed diseases. They gave very vague responses to the questions regarding immunization status of their reference child. Living below the poverty line they can hardly afford the transport expenses to the medical facilities, frequently.

Regarding the role of health care workers, it can be concluded that ASHA workers played a positive role during pre-natal period but had not advised the mothers regarding postnatal check-ups. All respondents gave colostrums to the child as the ASHA workers had advised them about this. The ANM played positive role during pre-natal period, but immunization advice was not given to most of the mothers after the birth of the child. Mothers were provided necessary information, regarding their new born, by the health staff during postnatal period, but since they had lost the Child Care Card the mothers were not able to tell the birth and post-natal history of their reference child. Mathew (2012) concluded that there are significant inequities in childhood vaccination based on various factors related to individual (gender, birth order), family (area of residence, wealth, parental education), demography (religion, caste), and the society (access to health-care, community literacy level) characteristics. Urban infants have higher coverage than rural infants and those living in urban slums. There is an almost direct relationship between household wealth and vaccination rates. The vaccination rates are lower among infants with mothers having no or low literacy, and families with insufficient empowerment of women (Mathew 2012). In the capital of this country, Elizabeth et al. (2015), in their study on slum dwellers of Delhi, found that majority of these slum women are ignorant about the importance of post-natal care which was necessary for post-delivery care of the women and her infant.

The correct knowledge on the importance of ANC and PNC and various checkups need to be carried out during pregnancy and postnatal period needs to be imparted to these women. Thus, health education and health promotion campaigns are needed for bring changes in the existing health-seeking 
behaviours among urban slum women (Elizabeth et al.,2015). It was observed that ASHA, doctors and ANM's played an important role during prenatal period, but during post-natal period, infancy and early childhood they did not play significant role.

Modi et al. (2014) conducted a study on the Health seeking behaviour of the Anganwadi Workers, the grassroot workers in the Integrated Child Development services scheme, having adolescent and maternal health as a key delivery area. The findings from their study assert that knowledge and awareness are not enough to motivate women to seek health care from the Government sector. The policymakers need to re-orient their priority towards these women health care providers who work at the grass root level and in fact are a "harbingers" of better health practices among women and children. They are the role models for their community, and their dismal performance in relation to their own health and government service utilization, may create a negative impact and reduce credibility (Modi et al., 2014).

Mothers were not aware about schemes launched by Government of India, for their welfare, but had availed some benefits due to them. All of them were BPL card holders and wished for more job opportunities from the Government. Most of them did not know about the $\mathrm{CMB}$, though some of them had received Rs 1400 under the JSSK. They were not aware that their treatment at the Governmental facility was free, as most of them said that they have to pay fees for that. They were also not aware of the SGSY, Swarnajayanti Gram Swarojgar Yojanaa, a development initiative launched by the Government of India to provide sustainable income to poorest of the poor people living in rural and urban areas of the country, or any other schemes in operation for the poverty alleviation. The findings of a contextual analysis on women's autonomy and pregnancy care in rural India indicate that women's autonomy was associated with greater use of pregnancy care services, particularly prenatal and postnatal care (Mistry et al 2009). The respondents in the present study were mostly home makers, having low level of education and were living in poor conditions. They were dependent on their husbands and other family members for seeking health care, though the grassroot level health workers were playing a positive role.

\section{CONCLUSION}

There is still a need to improve the outreach of the developmental programs by using a multipronged approach:

a) Generating awareness among the women regarding the developmental and health initiatives is essential because in the present study most of the women were not aware of the schemes or the benefits or facilities they could avail from these. Till this happens the programs will not reach the grassroots. The Grassroot level heath workers should make the target groups aware of the complete package of schemes of maternal and child health.

b) Awareness regarding Post-natal care needs to be increased and all the grassroot level health workers have to converge their efforts regarding this. Though Anagnwari worker has a big role to play here, yet she is entrusted with so many responsibilities that she may not be able to do justice to the maternal and child health during infancy and early childhood on her own. She needs support for the other functionaries too.

c) Education is related to many indicators of maternal and child health. The Right to Education is granted by the Constitution of India, free and compulsory education is provided till 14 years of age, but still education is not a priority in families living below poverty line, where it is difficult to make the two ends meet. The awareness regarding the importance of education still needs to be generated in the rural and tribal areas, and the urban slums, among the 
populations which have been marginalized, especially the females. Adult or continuing functional education programs should be extensively developed.

c) Government is taking a lot of initiatives but still somehow the maternal and child health seems to be improving at a very slow pace because of lack of ownership among the common people. People's participation has to be increased. This is possible only when each core worker and each individual feel it their responsibility to seek health.

d) Awareness regarding the poverty alleviation programs also needs to be generated. The families living below poverty line can take help of such initiatives to improve their financial conditions which will ultimately influence the maternal and child health status.

e) All the schemes of the government are now linked to ADHAAR, the unique identification number. The mothers need to be registered for the Direct Transfer of Benefits and for tracking them too, so that they could avail the benefits and be monitored.

f) The local self-governance institutions, under Panchayati Raj, need to be strengthened and made responsible for the maternal and child health care.

g) Though Health Providers in India are overburdened with the care, yet they need to be sensitized about the need for dignity among all the citizens, as many women refuse institutional deliveries due to lack of emotional support from the health care staff.

\section{REFERENCES}

Aneesha. 2015, 'Reproductive Health Issues of Woman in Tribal Setting', International Journal of Preventive Curative and Community, vol. 1, no. 4, pp. 172-174.

Annual Report 2013-2014, Department of Health \& Family Welfare, Ministry of Health \& Family Welfare
Government of India, <http://nhm.gov.in/images/pdf/media/ publication/Annual Report-Mohfw.pdf $>$, accessed Dec 27, 2017.

Bonu, S., Bhushan, I., Rani, M., Anderson, I. 2009, 'Incidence and Correlates of 'Catastrophic' Maternal Health Care Expenditure in India', Health Policy Plan, vol.24, pp. 445-456.

Census of India, 2011, <http://www.dataforall.org/dashboard/censusinfoin dia_pca>, accessed December 13, 2012

Census of India, SRS 2001-2003, <http://censusindia.gov.in/Vital Statistics/

Summary Report Death 01 03.pdf>, accessed April 3, 2012.

Dandappanavar, A. A. \& Khan, C. G. 2014, 'Healthseeking Behaviour and Ante Natal Period among the Women of Jannath Nagar: An Urban Slum of Dharwad Town (Karnataka)', Journal of Global Research Analysis, vol. 3, pp. 1-2.

Das, S., Bapat, U., More, N. S., Chordhekar, L., Joshi, W., Osrin, D. 2010, ' Prospective Study of Determinants and Costs of Home Births in Mumbai Slums', BMC pregnancy Childbirth, vol. 10, pp.38, doi:10.1186/1471-2393-10-38.

Deoki, N., Malini, S., Tripathy, R.M., Khattar, P., Nair, K.S., Tekre, Y.L. 2008, 'A Rapid Appraisal on Functioning of Janani Suraksha Yojana in South Orissa, New Delhi.', Journal of National Institute of Health and Family Welfare, Retrieved from Paa 2013, Princeton.edu/papers/131692.

Devasenapathy, N., George, M.S., Ghosh, J.S., Singh, A., Negandhi, H., Alagh, G., Shankar, A.H., Zodpey, S. 2014, 'Why Women Choose to give Birth at Home, A Situational Analysis from Urban Slums of Delhi'. BMJ Open, vol. 5, pp. 22-24.

Devasenapathy, N., Ghosh, J.S., Allen, E., Sharma, S., Shankar, A.H., Zodpey, S. 2015, 'Reproductive Healthcare Utilization in Urban Poor Settlements of Delhi:Baseline Survey of ANCHUL (Ante Natal and Child Health care in Urban Slums) Project', BMC Pregnancy Childbirth, vol.8, no. 15, pp. 212.

Elizabeth, A.M., Khan, A.M., Wahid, R. 2015, 'Reproductive Health Care Seeking Behavior among Urban Slum Women of Delhi', Journal of Educational Health Promotion, vol. 4, no. 87, doi: 10.4103/22779531.171800

Ganjiwale, J. 2012, 'Current Health Status of Women in India- Issues and Challenges', Journal of Health Line, vol. 3, no. 2. 
Gupta, M., Thakur, J.S., Kumar, R. 2008, 'Reproductive and Child Health Inequalities in Chandigarh Union Territory of India', Journal of Urban Health, vol. 85, pp. 291-299.

Griffiths, P. \& Stephenson, R. 2001, 'Understanding users' Perspectives of Barriers to Maternal Health Care use in Maharashtra', Indian Journal of Biosocial Science, vol. 33, pp. 339-359.

Joe, W., Sharma, S., Sharma, J., Shanta, Y.M. Ramanathan, M., Mishra, U.S., Subha, S.B., Kotechal, P.V., Patel, S.V., Shah, S., Katara, P., Madan, G. 2012, 'Health Seeking Behavior and Utilization of Health Services by Pregnant Mothers in Vadodara Slums', Journal of Health Line, vol. 3, no. 30.

Joe, W., Sharma, S., Sharma, J., Shanta, Y.M., Ramanathan, M., Mishra, U.S., Sri, B.S. 2015, 'Maternal Mortality in India: A Review of Trends and Patterns', Institute of Working Growth, no. 353, pp. 01-32.

Loudon (2000). Maternal Mortality in the Past and its Developing Counters Today. The American Journal of Council Nutrition, 72(1), 241-246.

Kumar, K., Faujdar, Ram., Singh, K. 2013, 'Public Spending on Health and Childhood Mortality in India', < http://ssrn.com/abstract=2240251 >

Loudon, 2000, 'Maternal Mortality in the Past and its Developing Counters Toda', The American Journal of Council Nutrition, vol. 72, no. 1, pp. 241-246.

Lule, E., Oomman, N., Eep, J., Huntington, D., Ramana, G., Rosen, E.J. 2005, 'Achieving the Millenium Developmental Goal of Improving Maternal Health Determinants, Interventions and Challenges.', Health Nutrition and Population Discussion Paper. www.WorldBank.Org.

Manna, P.K., De, D., Ghosh, D. 2011, 'Knowledge Attitude and Practices for Antenatal Care and Delivery of the Mothers of Tea Garden in Jalpaiguri and Darjeeling Districts, West Bengal', National Journal of Community Medical, vol. 2, pp.4-8.

Mathew, J.L. 2012, 'Inequity in Childhood Immunization in India: A Systematic Review', Journal of Indian Pediatrics, vol. 49, no. 3, pp. 203-23.

MDG Report, 2015, <http://www.un.org/millenniumgoals/2015_MDG_R eport/pdf/ MDG\%

202015\%20rev\%20(July\%201).pdf> accessed

December 12, 2017.

Mistry, R., Galal, O., Lu, M. 2009, 'Women's Autonomy and Pregnancy Care in Rural India: A
Contextual Analysis', Journal of Social Science and Medical, vol. 69, no. 6, pp. 926-33.

Modi, A., Moitra, M., Patel, B., Kantharia, S. 2014, 'Analysis of Health Seeking Behavior Among Women Healthcare Providers', Canadian Journal of Medical Research, vol. 1, no. 1, pp.1-4.

NFHS III report: Key Indicators of India from NFHS-3, $<$ http://www.nfhsindia.org/pdf/India.Pdf>, accessed December 112017.

NFHS IV report, <rciips.org/NFHS/pdf/NFHS4/India.pdf>, accessed December 112017.

Rakesh, P. \& Patail, K.S.M. 2012, 'Mother and Child Health. A Study of BPL Families with Social Work Perspective', International Journal of Indexed and Reffered Research, vol. 5, no. 6, pp. 63-64.

Sameh, El-S., Naoko,O., Intissar,S., Federica, S. \& Vikram, R.(2014). India: Maternal and Reproductive Health at a Glance. Health, Nutrition, and Population Global Practice Knowledge Brief; World Bank, Washington, DC. World Bank. https://openknowledge.worldbank.org/handle/1098 6/21291 License: CC BY 3.0 IGO."

Sameh, El-S., Naoka, O., Intisaar, S., Fedrica, S., Vikram, R. 2014, 'India: Maternal and Reproductive Health at a Glance. Health, Nutrition, and Population Global Practice Knowledge Brief', World Bank, Washington, DC, < https://openknowledge.worldbank.org/handle/1098 6/21291>

Sanneving, L., Trygg, N., Saxena, D., Mavalanakr, D., Thomsen, S. 2013, 'Inequity In India: The Case of Maternal and Reproductive Health', Journal of Global Health Action, vol. 6, no.10, doi: 10.3402/gha.v6i0.19145

Subha Sri, B. \& Khanna, V. 2014, 'Dead Women Walking: A Civil Report on Maternal Deaths in India', Common Health, Jan Swasthya Abhiyan.

Thomas, H. 1998, 'Reproductive Health Needs across the Lifespan. Women and Health Services: An Agenda for Change', Buckingham: Open University Press. The Tribune, 2017, $<$ http://www.tribuneindia.com/news/iammukashmir/community/ 10-35-population-belowpoverty-line-in-j-k-report/350038.html >, accessed December 132017.

UNICEF， <http://unicef.in/Whatwedo/1/MaternalHealth; http://in.one.un.org/page/ sustainable development-goals/sdg-3-2/> 
Sharma et al., 2018, European Journal of Social Sciences (EJSS), vol. 1, no. 1, DOI:10.29198/ejss1803

Vora, K.S., Mavalankar, D.V., Ramani, K.V., Upadhyaya, M., Sharma, B., Iyengar, S., Gupta, V., lyengar, K. 2009, 'Maternal health situation in India: A case study', $\underline{J}$ Health Popul Nutr, vol. 27, no. 2, pp. 184-201.

Vijay, A., Paul, R., Kalidas, P., Sujatha, K., Senthilkumar, S.K., Sreesupria, P. 2017, 'A Study on Health Seeking Behavior among Married Reproductive Age Group Women in a Rural Area', IOSR Journal of Dental and Medical Sciences, vol, 16, no. 3, pp. 08-11.

World Bank, 2016, <http://www.worldbank.org/en/news/infographic/2 $\underline{016 / 05 / 27 / \text { india-s- poverty- profile }>\text {, accessed }}$

December 132017.

WHO, 2015,

<http://www.searo.who.int/entity/health situation trends/countryprofile ind.pdf? ua $=1>$, accessed

December 132017. 